\title{
Solar assisted vapor absorption cooling system: A review
}

\author{
Saad Ahmed ${ }^{1}{ }^{*}$, M. Nasir Bashir ${ }^{2}$, Shah Zaib Umar ${ }^{3}$, Hamza Khan ${ }^{4}$ \\ 1,2 National University of Sciences and Technology, Islamabad, Pakistan \\ ${ }^{3,4}$ Air University, Islamabad, Pakistan
}

\author{
Keywords \\ Vapor absorption refrigeration \\ VAR cooling system \\ Solar assisted cooling \\ Portable refrigeration
}

Received: 8 April 2020

Accepted: 17 July 2020

Published: 16 November 2020

\begin{abstract}
Absorption Refrigeration System can play a vital role in electrical energy conservation because they can be operated on waste heat energy. The intermittent nature of solar power may be a dominant think about exploring well-designed thermal energy storages for consistent operation of solar thermal-powered vapor absorption systems. Our goal is to design the cooling unit based on a vapor absorption system. For this purpose, we have done a literature survey, mathematical modeling, simulations, and made computer-aided design models of our unit. We verified our component operating conditions.Thermal energy storage acts as a buffer and moderator between solar thermal collectors and generators of absorption chillers and significantly improves the system performance. Vapor absorption chillers are available in half, single, double, and triple-effect modes of operation and operate at temperatures starting from 75 to $220^{\circ} \mathrm{C}$ to supply a cooling effect with COPs starting from 0.3 to 1.8 . Thus, the choice of appropriate solar collectors and thermal energy storages are two significant decisions affecting the consistency of output of a vapor absorption cooling system. This review covers all the major aspects of such systems. It also covers the research work done on this subject till now. Though there is still room for a lot of research work in this area of refrigeration systems. Moreover, the conclusions and recommendations are also discussed.
\end{abstract}

(C) 2020 The Author(s). Published by TAF Publishing.

\section{INTRODUCTION}

\section{A. Background}

A vapor absorption system is a system, which produces a refrigeration effect using a heat source [1]. It looks awkward to achieve refrigeration effect i.e., cooling with heat, but that is what takes place inside an absorption system. A solution of lithium bromide and water is used in commercial VARS (Vapor Absorption Refrigeration System). The refrigerant, which is used in that system is water, as with the help of that cooling is achieved. The other thing that drives the process is salt, generally lithium bromide. Waste heat is provided to detach these two fluids when they are mixed. in very lowpressure conditions [2].

For very low-temperature applications i.e., negative temperatures, ammonia vapor absorption systems utilize am- monia as a refrigerant while water as an absorbent. These systems use a minute fraction of electricity or no electricity as compared to the vapor absorption systems. Vapor absorption system generally works with nonchlorofluorocarbon environment-friendly refrigerants such as water and ammonia.

The cost of VARS larger than that compression. systems, but when observed deeply the reduced electrical cost, transformers, switch gears, cabling, etc., the VARS becomes comparable with that of compression systems. Absorption refrigeration systems are used in recreational vehicles where food is stored. This system can also be used in the airconditioning of buildings by using the waste heat from the water heaters or gas $[3,4]$ turbines. This makes the turbines more efficient because firstly it produces electricity, then warm water and in the end air-conditioning.

\footnotetext{
${ }^{*}$ Corresponding author: Saad Ahmed

†email: Sahmed.mech@gmail.com
} 

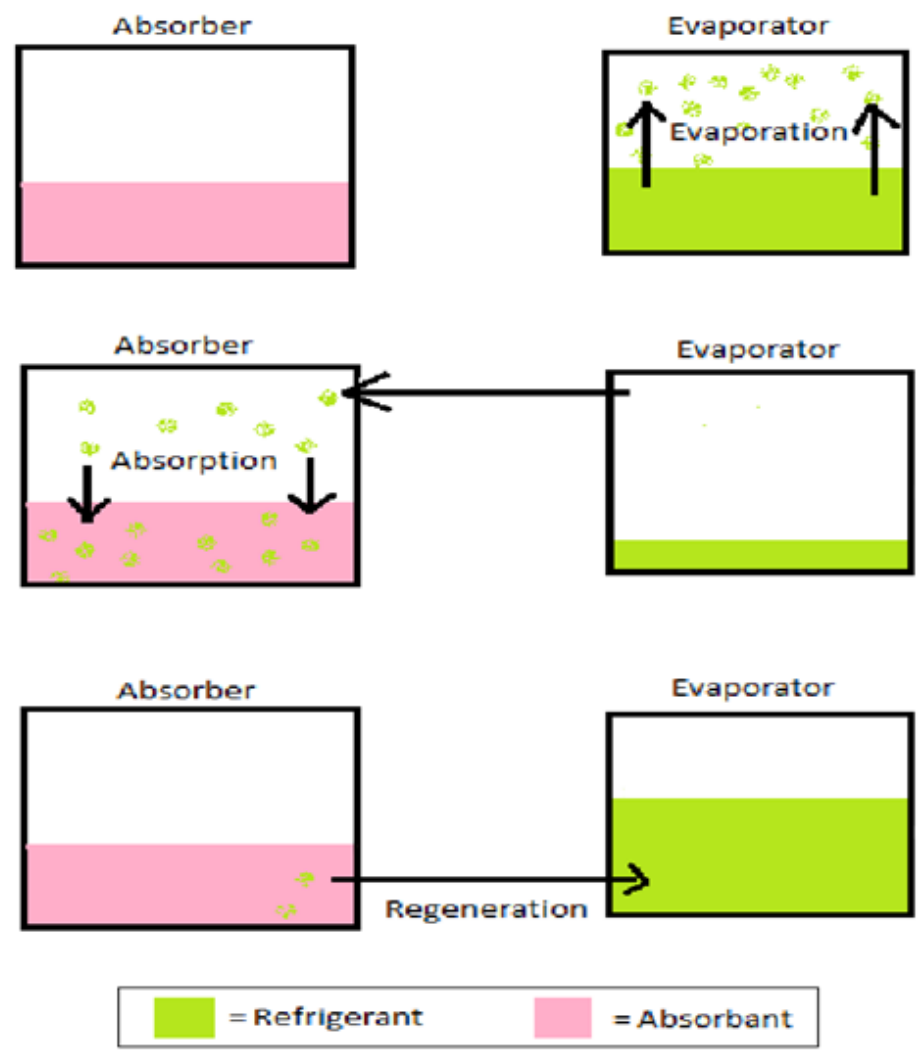

Fig. 1. Schematics of VAR system

TABLE 1

COMPARISON BETWEEN VCR AND VAR SYSTEMS

\begin{tabular}{|c|c|c|c|}
\hline Sr.No. & Characteristics & Vapor Compression Refrigeration Systems VCRS & Vapor Absorption Refrigeration Systems VARS \\
\hline 1. & Energy input & $\begin{array}{l}\text { Vapor compression systems require a high grade of } \\
\text { energy. }\end{array}$ & $\begin{array}{l}\text { Vapor absorption systems require a low grade of } \\
\text { energy. }\end{array}$ \\
\hline 2. & Moving part & A compressor is the moving part of that system. & The pump is the moving part of that system. \\
\hline 3. & Capacity & $\begin{array}{l}\text { Difficult to achieve } 1000 \mathrm{TR} \text { with single compres- } \\
\text { sion systems. }\end{array}$ & Above $1000 \mathrm{TR}$ is easily achievable. \\
\hline 4. & Refrigerant & $\begin{array}{l}\text { Hydrocarbon, chlorofluorocarbons, and } \mathrm{Hy}- \\
\text { drochlorofluorocarbons can be used. }\end{array}$ & Water and Ammonia can be used. \\
\hline 5. & Evaporators exit & $\begin{array}{l}\text { In the compression systems, the refrigerant should } \\
\text { in the vapor phase at the evaporator exit. The liq- } \\
\text { uid refrigerant is not desirable in compression sys- } \\
\text { tems. }\end{array}$ & $\begin{array}{l}\text { In the absorption systems, if a liquid refrigerant } \\
\text { leaves the evaporator, their refrigeration effect is } \\
\text { reduced but there is no effect on the system. }\end{array}$ \\
\hline 6. & Working at Variable Load & It does not work well at variable loads. & Variable loads do not affect that system. \\
\hline 7. & Lowest temperature & Very low temperature can be achieved. & $\begin{array}{l}\text { Temperature above } 0^{\circ} \mathrm{C} \text { can be achieved when wa- } \\
\text { ter as a refrigerant is used. }\end{array}$ \\
\hline 8. & Coefficient of performance & $\begin{array}{l}\text { The COP of compression systems Are generally } \\
\text { high. }\end{array}$ & The COP of absorption systems is generally low. \\
\hline 9. & Evaporator pressure effect & $\begin{array}{l}\text { The very little effect occurs in refrigeration Capac- } \\
\text { ity. }\end{array}$ & Refrigeration capacity generally decreases. \\
\hline
\end{tabular}

\section{B. Rational of the Study}

As the name of our project suggests our project works on heat obtained from solar energy. To obtain heat we have required to set up a solar geyser. A study is given in this journal that compares different photovoltaic systems and their efficiencies $[5,6]$. As absurd as it sounds the main driving force in solar absorption refrigeration systems is the Heat(thermal) power from solar energy collectors. In addition to this, a comparative study is given on photovoltaic systems. These PVT systems are as follows. ETC Evacu- 
ated solar collector tubes, PTC parabolic trough solar collectors, CPC: Compound Parabolic Concentrator LCC: Linear concentrating collector. The research work obtained from a comparison of data and their efficiencies are given in the manner of tables which are proven to be very fruitful for our research work. The main setback of this system is that they are expensive. Using these principles, we are going to decide the most cost-effective and yet efficient solar system for our project. Our main objective of the project is portability [7]. With the help of the parametric study given in this journal, we are designing a foldable solar collector.

With help of mathematical modeling, we can find the optimal parameters for the main components of our final year projects such as Evaporator, Absorber, Generator, and Condenser [8]. Quality Coefficient. Thermal loads of all materials, quality of electricity and. The overall change in energy of all the elements of the absorption cooling system is planned for a variety of operating conditions. The working parameters that are checked in the simulation of the refrigeration processes are the evaporator, condenser, and generator temperatures $4^{\circ} \mathrm{C} 10^{\circ} \mathrm{C}, 33^{\circ} \mathrm{C} 39^{\circ} \mathrm{C}$ and $50^{\circ} \mathrm{C} 240$ (Ahmed Hamza H. Ali, 2019) C, respectively, and their spectrum of variations changed addition, the temperature of the generator depends on the temperature of the evaporator. COP increases with increases in evaporator temperature for the given generator temperature, while COP decreases by increasing condenser temperature. Exegetic efficiency is found to improve initially and then decrease as the temperature of the generator increases when exergy varies overall [9]. Initially, all components decrease and then rise with the temperature of the engine. Optimum generator temperatures are available, leading to maximum exegetical efficiency and a minimal total change in energy [10].

Our system depends on four main chambers namely Condenser, Evaporator, Absorber, and Generator. As our system operates on low-pressure conditions so we need to rectify some of the facts. These four chambers are very important to us, but the other important thing is the use of pumps and heat exchangers. We do not take them ideally. Pump work cannot be neglected in actual absorption cycles because it directly affects the actual COP of the system. The second thing which I want to define here is the "effectiveness of Heat exchanger". The heat exchanger does not directly relate to the Actual COP of the system, but it affects the Generator Heat Input which is related to the COP of the system. Secondly, we want to define a parameter, which relates to them. We cannot neglect any single parameter. We do thermo-dynamical analysis by defining some actual parameters. In the end, we correlate the actual theoretical COP to the practical COP of the system. As far as fabrication is concerned, it is easy when you theoretically complete the whole process. But proper concentration is required because a small leakage will have a bad effect on the system [11].

The absorber is the component of the absorption system; in general, its performance impacts directly the size and energy supply of all absorption devices. The absorber operates at low temperatures in absorption cooling systems, so the mass transfer is an important phenomenon for minimizing the generator size and strength of the pumps. The heat and mass transfer combinations contribute to problems that exist in absorbers. So, if we build an absorber, we should first bear in mind the following things.

\section{Purpose of the Study}

- The vapor and absorbent interface surface needs to be as wide as possible.

- The boundary layer of the absorbent needs to be constantly refreshed.

- It is important to withdraw the absorption heat at about the same location as it is formed.

\section{Significance of the Study}

Analysis indicates the conversion of mass and heat. The efficacy of the absorber has a direct impact on the efficiency duration of the absorber. The efficacy of the absorber will decrease the supply of generator waste heat when absorber dilution has a high value and, thus, increase the COP [7]. In this study, the thermal simulations are done on an Engineering Equations solver. This is done with the help of newly added libraries of $\mathrm{LiBrH}_{2} \mathrm{O}$ and SSC. These libraries are quite adequate for simulations. Our simulation is done by using the iterative method using numerical equations. The graphs are plotted in MATLAB which provides sufficient information [12]. In solar absorption chillers, direct normal irradiance (the amount of solar radiation obtained per unit area by a surface which is often kept perpendicular (or normal) to the rays) plays an important part. The research has been done to study the effect of DNI under global horizontal irradiance (total amount of shortwave radiation received from above by a surface horizontal to the ground.) to know which Absorption chiller is most effective. The study reveals that solar multi-effect absorption systems have a little practical benefit over single-stage absorption systems when DNI is below 60 percent of maximum global solar irradiance. In climates where the DNI fraction is above 60 percent, a substantial decrease in the size of the solar field can be achieved $[13,14]$. 
To study the complete cycle, the thermodynamic properties of each point are found first. As the state points are difficult to determine, the following assumptions are applied to the system.

\section{E. Assumptions}

Heat and pressure losses across the components are negligible.

- The refrigeration agent exiting the condenser and evaporator are saturated points i.e., (points 8 and 10).

- Strong solution leaving the generator (point 4) and weak solution leaving the absorber (point 1 ) also assumed to be saturated.

- Refrigerant is also assumed in a superheated state at the generator temperature (point 7).

- Pump work is considered as isentropic and adiabatic. With the assumption, energy and mass balance are applied at each component, and state points are calculated by the Duhring Chart.

\section{LITERATURE REVIEW}

Everyone has energy scarcity anxieties, in part, because experts predict that fossil fuel resources will be depleted in the next half century. In fact, the development and welfare conditions of entire countries are largely dependent on energy, and as a result, experts are devoting increased attention to renewable energy sources. A second potential fear is global warming due to an increase in global temperature (about 0.6 degrees Centigrade). Based on information provided by the UN governmental panel on climate change, this panel has warned that the temperature could rise by a further 1.4 to 4.5 degrees Centigrade if current warming trends continue. Global warming has already begun to have an impact on our everyday lives, with dire ramifications for Earth's ecology. Besides catastrophic weather and increasing danger from nature, other global warming-related consequences include melting polar ice caps, more seismic activity, more frequent and intense hurricanes, glacier retreat, rising sea levels, higher concentrations of ozone in the lower atmosphere, and extreme weather. The effects on the economy are also apparent, such as the recent rise in the price of oil in 2008 that followed from the increase in the price of oil that occurred during the 1970 s oil crisis.

\section{A. Enthalpy Values for the Refrigerant (Liquid and Su- perheated Vapor)}

The enthalpy of water in the liquid state at all temperatures and pressure are calculated with the help of water property data. For all practical application, the enthalpy of water in the liquid state is calculated as:

Where $T_{r e f}$ is the reference temperature, $0^{\circ} \mathrm{C}[15]$.

$$
h_{w}=4.19\left(T-T_{r e f}\right)
$$

\section{B. Charts}

The chart as shown in Figure 2 is used to find out the enthalpy of the solution by knowing the temperature as well as the mass concentration of the solution [2]. The chart shown in Figure 2 defines the pressure of the solution at the generator and absorber exit by knowing the temperature and concentration of the solution at the generator exit and absorber exit [10]. The graph provided in Figure 3 gives the details about the concentration of refrigerant salt [5]. 


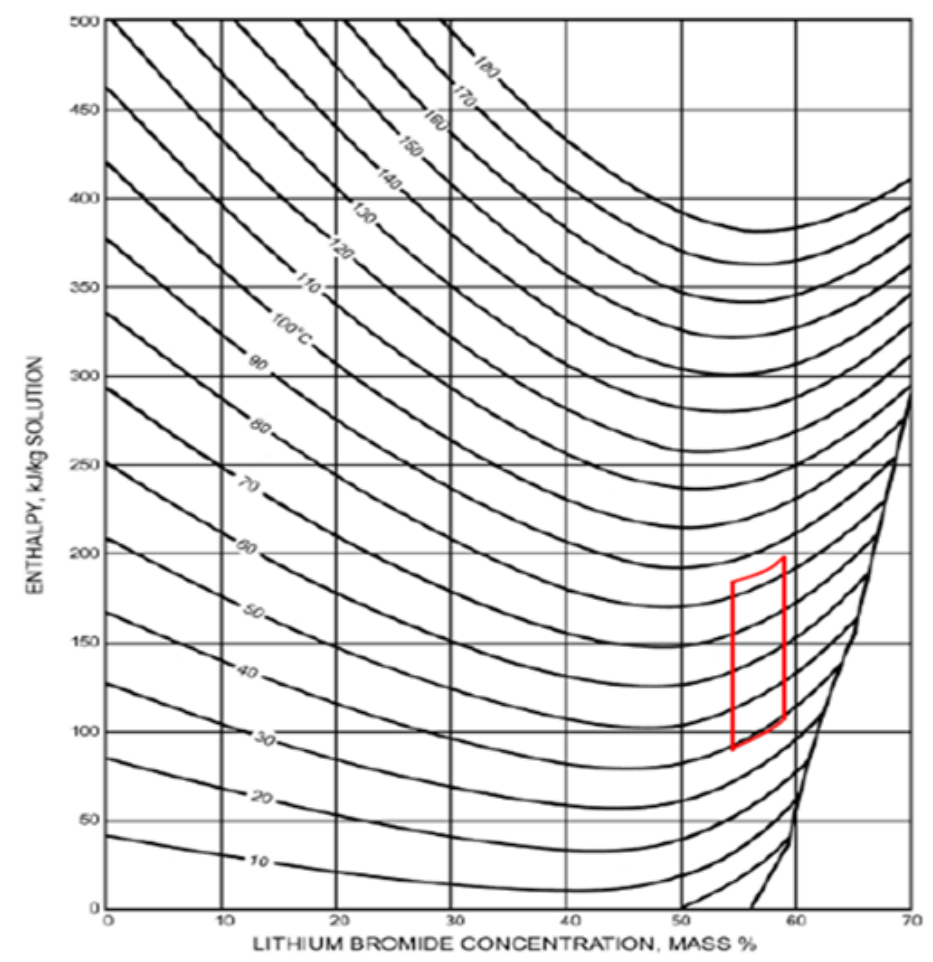

Fig. 2. Enthalpy vs Li-Br concentration

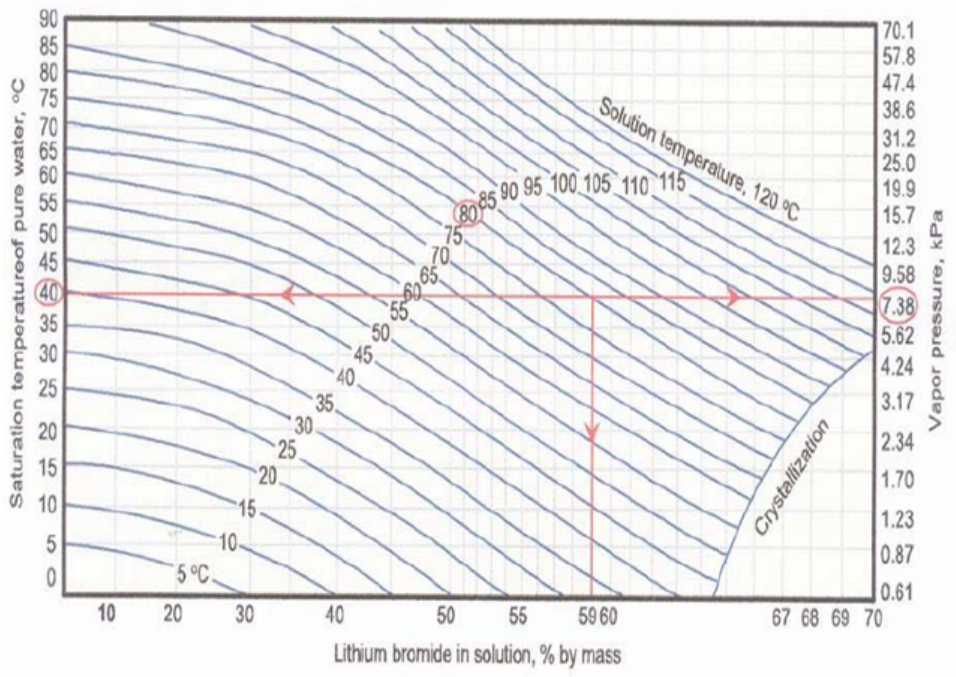

Fig. 3. Saturation temperature and vapor pressure

\section{THEORETICAL ANALYSIS}

Water tank is the primary component of a solar absorption cooling system. The whole system functionality depends on these three components working together. Computer simulations and analyses using programmes likeTRNSYS. a study that looks at whether solar absorption cooling works in Tunisia $[16,17]$. The weather model was based on TRNSYS and EES, as well as a file including meteorological year data from the city of Tunis, Tunisia. In the example building, the optimised system included an $\mathrm{AIT} /{ }_{2} \mathrm{O}$ absorption chiller with an acapacity of $11 \mathrm{~kW}$, and a tilt of 351 with respect to the horizontal to create a $30 \mathrm{~m}^{2}$ flat-plate solar collector. To meet the cooling needs of a typical house in Cyprus, they built a $\mathrm{LiBr} / \mathrm{H}_{2} \mathrm{O}$ absorption unit with the cooling capacity of $11 \mathrm{~kW} .15 \mathrm{~m}^{2}$ compound parabolic collectors, which were tilted at a 301-degree angle, and a 600-liter hot water storage tank were placed in an optimised layout to get the ideal system. As Assilzadeh et al. [18] found, an evacuated tubular solar collector has been built for Malaysia and other tropical countries in order to absorb solar radi- 
ation and utilise it for a water-based absorber containing $\mathrm{LiBr}$ and $\mathrm{H}_{2} \mathrm{O}$. It was proven that in order to maintain continuous operation and improve system reliability, a $0.8 \mathrm{~m} 3$ hot water storage tank was required. To provide the maximum possible shade and comfort, the $35 \mathrm{~m}^{2}$ evacuated tube solar collector is positioned to collect $3.5 \mathrm{~kW}$, has a slope of 201, and is set on an $8.5 \mathrm{~cm}$ thick concrete slab. Joudi and Abdul-Ghafour [19] developed a solar cooling system that would only use a steady $10.5 \mathrm{~kW}$ of cooling power. The method was designed so that a modular computer software may be used to study various cycle and solar energy factors in Antalya, Turkey. The storage tank's weight of $3750 \mathrm{~kg}$ was seen to be most effective when compared to the area of 50 $\mathrm{m}^{2}$ that housed the solar collector. Using an integrated simulation model, Mammoli et al. [20] built a comprehensive simulation model for a solar water system with a $\mathrm{LiBr} / \mathrm{H}_{2} \mathrm{O}$ absorption chiller. Simulation results were utilised to construct a design approach for solar cooling systems. This procedure, referred to as the cooling fchart, was illustrated as a graphic representation. To anticipate the long-term cooling energy supplied by a solar collector array, which serves an absorption-chilled water system, using this design chart should be quite simple. Furthermore, it was established that using the simulation results for calculating the required hot water storage size for the solar cooling system, a correlation was found [21].

The composition of a solar cooling system is based on factors including the demand for cooling, solar resource availability, meteorological conditions, and the price and features of the components. It was reported to have a specific cooling capability of $0.1-0.7 \mathrm{~kW} / \mathrm{m}^{2}$. $\mathrm{LiBr}-\mathrm{H}_{2} \mathrm{O}$ absorption heat pump was modelled by mathematician [21] to demonstrate how a single effect can be used in a heat pump application. His calculations took into consideration the presence of mass and heat transfer coefficients, temperature distribution, flow characteristics, fluid heat and mass transfer, as well as the dangers posed by the LiBr aqueous solution hydrates and crystallisation. It was found that vapour mass flux rose as the concentration of the solute was increased, the flow rate of the cooling agent was increased, and the density of the liquid being sprayed was decreased. Absorber pressure caused the vapour mass flux to grow approximately linearly [22]. Using this approach, it is found that experimental results exhibit agreement within 7 percent. To facilitate the crystallisation challenges and control techniques in $\mathrm{LiBr}-\mathrm{H}_{2} \mathrm{O}$ air-cooled absorption chillers, Prasartkaew and Kumar [23] looked into their formation and control procedures. To elaborate, he points out six potential triggers for crystallisation: a very high ambient tem- perature; excessively hot conditions; some air leaking into the machine, especially in a heavily loaded system; gas leakage due to corrosion, most notably CO; large amounts of heat input; no recovery after shutting down; and the temperature of the chilled water supply is too low, even in hot conditions [24]. In order to execute an experimental and simulation analysis on a laboratory single-stage $\mathrm{H}_{2} \mathrm{O}-\mathrm{LiBr}$ absorption heat pump with a cooling capacity of $14 \mathrm{~kW}$, [24] devised an experiment that would better approximate the operating conditions of the pump. Results showed that design factors of the machine and the temperatures of chilled, cooling, and hot water were significant operating parameters. An $\mathrm{H}_{2} \mathrm{O}$ - $\mathrm{LiBr}$ absorption heat pumps design and dimensioning model was constructed. Simulation findings of the model were compared with experimental measurements to ascertain the model's accuracy [25].

\section{CONCLUSION}

From our experimental simulations, we have also chosen our operating conditions of the system. Which are as follows.

- Absorber Temperature $=30-35$ Celsius

- Generator Temperature $=80-90$ Celsius

- Condenser Temperature=33-38 Celsius

- Evaporator Temperature $=10$ Celsius

These conditions will yield the maximum coefficient of performance (COP) [16] i.e., 0.8 .

Mass flow rates and circulation ratio will be set accordingly. The effectiveness of heat exchangers will be less than ' 1 ' in real cases. Which also affects the performance of the system. These are the parameters of the ideal case scenario. In the actual system, many losses occur that affect the performance of the system. From the fabrication perspective, it is not as much costly as it thought. From the refrigerant perspective, it is costly. But the refrigerant like lithium bromide easily dissolves in water like we made 55 percent concentration easily.

It is determined that the $\mathrm{LiBr}_{-2} \mathrm{O}$ single effect absorption cooling method is better-suited for home use. This setup is better served with flat plate and evacuated tube solar collectors. The two main factors affecting the most economical solar air-conditioning system are discovered to be the heat load and power requirements. It includes: solar energy gathering and storage system costs 2 . The cooling technologies' performance. Furthermore, several proposals were formulated based on two factors, such as these: (i)With the solar thermal collector above the hot water storage tank and the thermo syphon method, hot water can be transferred to the tank. (ii)Since water loses heat when transferred, heat 
loss when using the solar thermal collector and the thermo syphon system is reduced by placing the generator inside the insulated storage tank. Furthermore, reducing the cost of insulation on the generator allows us to do (ii) By increasing the vacuum pressure in the cooling circuit, we increase the boiling point of water within the generator (iv). There are just three significant electrical appliances that utilise the innovative concept presented in this study (condenser fan, cooling coil fan and a pump). To thus greatly reduce operational cost, compression is a very efficient technology. This solar system costs more to buy up front, but there are several ways to keep operational costs low. Due to this, the long-term operational assessment results show that compression cooling systems are competitive when compared to solar-assisted single effect absorption cooling systems.

\section{A. Limitations of Study}

Based on the literature review the Vapor absorption technology deserves the attention of the research industry. To make our system more efficient, work must be done, to design, two or three-stage absorption system. Initial cost does exceed the usual cost of a compression system, but this can be resolved by improved design and mass production. Our prototype (with further Research and Design) can be commercialized. Air conditioning and refrigeration can both be revolutionized absorption technology. One more thing which is under consideration is that this system operates with waste heat which is a big advantage. Solar panels and solar geysers are present that is the required term for absorption systems.

\section{REFERENCES}

[1] Y. A. Cengel, M. A. Boles, and M. Kanoglu, Thermodynamics: An Engineering Approach. New York, NY: McGraw-hill, 2011.

[2] A. Yokozeki, "Theoretical performances of various refrigerant absorbent pairs in a vapor-absorption refrigeration cycle by the use of equations of state," Applied Energy, vol. 80, no. 4, pp. 383-399, 2005. doi: https://doi.org/10.1016/j. apenergy.2004.04.011

[3] I. Sujatha and G. Venkatarathnam, "Comparison of performance of a vapor absorption refrigeration system operating with some hydrofluorocarbons and hydrofluoroolefins as refrigerants along with ionic liquid as the absorbent," International Journal of Refrigeration, vol. 88, pp. 370-382, 2018. doi: https://doi.org/10.1016/j.ijrefrig.2018.03.004

[4] O. A. Osahenvemwen and O. F. Odiase, "Effective management of handover process in mobile communication network," Journal of Advances in Technology and Engineering Studies, vol. 2, no. 6, pp. 176-182, 2016. doi: https://doi.org/10. 20474/jater-2.6.1

[5] M. Mehrabian and A. Shahbeik, "Thermodynamic modelling of a single-effect LiBr-H2O absorption refrigeration cycle," Proceedings of the Institution of Mechanical Engineers, Part E: Journal of Process Mechanical Engineering, vol. 219, no. 3, pp. 261-273, 2005. doi: https://doi.org/10.1243/095440805X8656

[6] S. M. Osta-Omar and C. Micallef, "Effect of the vapour-solution interface area on a miniature lithium-bromide/water absorption refrigeration system equipped with an adiabatic absorber," Energy Procedia, vol. 118, pp. 243-247, 2017. doi: https://doi.org/10.1016/j.egypro.2017.07.009

[7] B. Kundu, P. Mondal, S. Datta, and S. Wongwises, "Operating design conditions of a solar-powered vapor absorption cooling system with an absorber plate having different profiles: An analytical study," International Communications in Heat and Mass Transfer, vol. 37, no. 9, pp. 1238-1245, 2010. doi: https://doi.org/10.1016/j.icheatmasstransfer.2010. 08.012

[8] M. Alobaid, B. Hughes, J. K. Calautit, D. O'Connor, and A. Heyes, "A review of solar driven absorption cooling with photovoltaic thermal systems," Renewable and Sustainable Energy Reviews, vol. 76, pp. 728-742, 2017. doi: https: //doi.org/10.1016/j.rser.2017.03.081

[9] G. D. Takalkar, R. R. Bhosale, N. A. Mali, and S. S. Bhagwat, "Thermodynamic analysis of EMISE water as a working pair for absorption refrigeration system," Applied Thermal Engineering, vol. 148, pp. 787-795, 2019. doi: https://doi.org/ 10.1016/j.applthermaleng.2018.11.092

[10] P. A. N. Wouagfack and R. Tchinda, "Finite-time thermodynamics optimization of absorption refrigeration systems: A review," Renewable and Sustainable Energy Reviews, vol. 21, pp. 524-536, 2013. doi: https://doi.org/10.1016/j.rser. 2012.12.015

[11] R. Maryami and A. Dehghan, "An exergy based comparative study between libr/water absorption refrigeration systems from half effect to triple effect," Applied Thermal Engineering, vol. 124, pp. 103-123, 2017. doi: https://doi.org/10. 1016/j.applthermaleng.2017.05.174 
[12] R. Porumb, B. Porumb, and M. Balan, "Numerical investigation on solar absorption chiller with LiBr-H2O operating conditions and performances," Energy Procedia, vol. 112, pp. 108-117, 2017. doi: https://doi.org/10.1016/j.egypro. 2017.03.1071

[13] A. Shirazi, R. A. Taylor, S. D. White, and G. L. Morrison, "Multi-effect absorption chillers powered by the sun: Reality or reverie," Energy Procedia, vol. 91, pp. 844-856, 2016. doi: https://doi.org/10.1016/j.egypro.2016.06.251

[14] M. A. Rawajbeh, I. A. Haddid, and H. Al-Zoubi, "Adoption of cloud computing in higher education sector: An overview," International Journal of Technology and Engineering Studies, vol. 5, no. 1, pp. 23-29, 2019. doi: https://dx.doi.org/10. 20469/ijtes.5.10004-1

[15] S. Raghuvanshi and G. Maheshwari, "Analysis of ammonia water (NH3-H2O) vapor absorption refrigeration system based on first law of thermodynamics," International Journal of Scientific \& Engineering Research, vol. 2, no. 8, pp. 1-7, 2011.

[16] S. Kaushik and S. Singh, "Thermodynamic analysis of vapor absorption refrigeration system and calculation of COP," International Journal for Research in Applied Science and Engineering Technology, vol. 2, no. 2, pp. 73-80, 2014.

[17] B. H. Gebreslassie, G. Guillén-Gosálbez, L. Jiménez, and D. Boer, "Solar assisted absorption cooling cycles for reduction of global warming: A multi-objective optimization approach," Solar Energy, vol. 86, no. 7, pp. 2083-2094, 2012. doi: https://doi.org/10.1016/j.solener.2012.04.010

[18] F. Assilzadeh, S. A. Kalogirou, Y. Ali, and K. Sopian, "Simulation and optimization of a LiBr solar absorption cooling system with evacuated tube collectors," Renewable Energy, vol. 30, no. 8, pp. 1143-1159, 2005. doi: https://doi.org/ 10.1016/j.renene.2004.09.017

[19] K. A. Joudi and Q. J. Abdul-Ghafour, "Development of design charts for solar cooling systems part i: Computer simulation for a solar cooling system and development of solar cooling design charts," Energy Conversion and Management, vol. 44, no. 2, pp. 313-339, 2003. doi: https://doi.org/10.1016/S0196-8904(02)00045-6

[20] A. Mammoli, P. Vorobieff, H. Barsun, R. Burnett, and D. Fisher, "Energetic, economic and environmental performance of a solar-thermal-assisted hvac system," Energy and Buildings, vol. 42, no. 9, pp. 1524-1535, 2010. doi: https://doi. org/10.1016/j.enbuild.2010.03.023

[21] A. Elsafty and A. Al-Daini, "Economical comparison between a solar-powered vapour absorption air-conditioning system and a vapour compression system in the Middle East," Renewable Energy, vol. 25, no. 4, pp. 569-583, 2002. doi: https://doi.org/10.1016/S0960-1481(01)00078-7

[22] M. Helm, C. Keil, S. Hiebler, H. Mehling, and C. Schweigler, "Solar heating and cooling system with absorption chiller and low temperature latent heat storage: Energetic performance and operational experience," International Journal of Refrigeration, vol. 32, no. 4, pp. 596-606, 2009. doi: https://doi.org/10.1016/j.ijrefrig.2009.02.010

[23] B. Prasartkaew and S. Kumar, "A low carbon cooling system using renewable energy resources and technologies," Energy and Buildings, vol. 42, no. 9, pp. 1453-1462, 2010. doi: https://doi.org/10.1016/j.enbuild.2010.03.015

[24] L. Jianhong, B. Ning, and M. Weibin, "Large solar powered air conditioning-heat pump system," Acta Energiae Solaris Sinica, vol. 27, no. 2, pp. 152-170, 2006.

[25] H.-M. Henning, "Solar assisted air conditioning of buildings an overview," Applied Thermal Engineering, vol. 27, no. 10, pp. 1734-1749, 2007. 